Moroccan higher education students' and teachers' perceptions towards using Web 2.0 technologies in language learning and teaching

Rdouan Faizi

ENSIAS

Mohammed V University, Rabat, Morocco

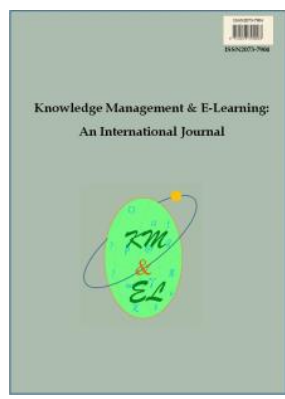

Knowledge Management \& E-Learning: An International Journal (KM\&EL) ISSN 2073-7904

Recommended citation:

Faizi, R. (2018). Moroccan higher education students' and teachers' perceptions towards using Web 2.0 technologies in language learning and teaching. Knowledge Management \& E-Learning, 10(1), 86-96. 


\title{
Moroccan higher education students' and teachers' perceptions towards using Web 2.0 technologies in language learning and teaching
}

\author{
Rdouan Faizi* \\ Rabat Information Technology Center \\ ENSIAS \\ Mohammed V University, Rabat, Morocco \\ E-mail: rdouan.faizi@um5.ac.ma \\ *Corresponding author
}

\begin{abstract}
The objective of this paper is to examine Moroccan higher education students' and teachers' perceptions and attitudes towards using Web 2.0 technologies in language learning and teaching. The results of the study revealed that all the informants were immersed in using these Internet-based applications for personal and educational purposes. Nevertheless, while language learners reported to make beneficial uses of these online platforms as language learning tools, the great majority of the interviewed faculty members did not really benefit from these platforms. Although language teachers acknowledged that Web 2.0 technologies had a positive impact on language teaching and learning, most of them were still reluctant to incorporate these tools in educational practice. The findings demonstrated that most teachers' use of these applications was limited to sending or transferring web links and learning materials produced by other Internet users. Rather than making effective use of Web 2.0 technologies and applications as teaching facilities, most teachers used them only as a means of communication.
\end{abstract}

Keywords: Web 2.0 technology; Language learning; Language teaching; Higher education; Perception; Attitude

Biographical notes: Rdouan Faizi is a Full Professor at ENSIAS, Mohammed $\mathrm{V}$ University in Rabat, Morocco. He is engaged in research in education technology and linguistics. He has published a number of papers in highly refereed journals and has participated in many international conferences.

\section{Introduction}

Over the past few years, the Internet has evolved from being a read-only platform that people used to access information into a read-write universal channel in which users are producers and consumers of digital content. In the past, the Internet was just a means for distributing static content produced by web experts. Common Internet users were only confined to the passive browsing of web pages. This means that they could not edit those pages, post reviews, add comments, or give feedback. In the last few years, however, the rapid advances in information and communication technology have resulted in the emergence of a new generation of Internet-based collaborative tools, commonly known as Web 2.0. The latter are a set of dynamic technologies where users can easily share and 
publish their information and at the same time connect with other users (Kumar \& Cohn, 2012). These platforms, to which any Internet user can have access, are of different categories but all share the common characteristic of creating and exchanging usergenerated content (Harris \& Rea, 2009).

Web 2.0 platforms can generally be divided into three categories. The first category consists of social online communities such as Facebook, Twitter, LinkedIn, Google+ and Viadeo, where people connect and interact with each other. The second category includes content sharing and organizing online platforms such as YouTube, Vimeo, Dailymotion, Dropbox, Slideshare, Digg, Delicious and RSS. The third category is composed of content creation and editing websites like discussion boards, Wiki, Blogger and WordPress. Nonetheless, the features and functions of each of these Web 2.0 applications often overlap, which makes a tool appropriate for more than one category.

Web 2.0 technologies are now widely used by millions of people around the world for a variety of reasons. Accordingly, they are rapidly changing the way individuals interact with each other and are providing organizations with innovative ways to target groups. The way these digital online tools impacts both our private and professional lives is, however, far greater than most of us can anticipate.

With the emergence and increasing use of these digital tools, a large number of students, faculty members and higher education institutions are embracing this new ecology of information for different purposes. The present work is, therefore, an attempt to investigate the potential impact that Web 2.0 technologies have on the way education is delivered. Yet, focus will be on how the new tools influence language learning and teaching.

The rest of this article is organized as follows. Section Two outlines the potential benefits of using Web 2.0 in education and in language learning and teaching in particular. Section Three presents and discusses the findings of the study we undertook to explore students' and language teachers' perceptions towards using these internet-based applications for language learning and teaching purposes. Finally, Section Four gives a brief conclusion.

\section{Web 2.0 in language learning and teaching settings: Potential benefits}

In an increasingly globalized world, speaking foreign languages has become a common practice. For this reason, many people have recourse to Web 2.0 technologies to foster their language skills. In fact, rather than being confined to traditional learning contexts, students and language learners in particular have recourse to these platforms to practice their language and communication skills (Faizi, El Afia, \& Chiheb, 2014; Emelyanova \& Voronina, 2017).

Following a number of studies, Web 2.0 applications present many educational benefits for both the student and the teacher. The first advantage of using these online tools is that they help develop a greater sense of community (Dawson, 2006). They also facilitate interaction and communication between faculty members and students within and between classes, and provide students with enough opportunities to get connected with each other and get involved in collaborative learning regardless of place and time (LeNoue, Hall, \& Eighmy, 2011; Kent, 2016). Via these online social spaces, students can interact, communicate, exchange ideas, and expand their knowledge base on different topics. By using these digital tools, students can ask questions concerning problems they may face while learning, and can get feedback from teachers or from other students in 
just a matter of minutes (Hao, Barnes, Branch, \& Wright, 2017). Similarly, instructors can, through these online applications, answer their students' queries, post or correct homework and provide help for students who are having learning difficulties. Thus, the potential use of Web 2.0 technologies as an interaction tool between students and teachers and among learners will certainly reinforce the achievement of positive student learning outcomes (Yu, Tian, Vogel, \& Kwok, 2010).

In addition to promoting interaction, Web 2.0 technologies are an efficient way to get students' engagement in meaningful learning processes (Annetta, Minogue, Holmes, \& Cheng, 2009; Chen, Lambert, \& Guidry, 2010; Faizi, El Afia, \& Chiheb, 2013; Junco, 2012). Engagement refers to the readiness, need, desire and compulsion of a student to actively participate in different school activities such as attending classes, adherence to the teacher's directives, as well as doing the required assignments (Kenny, Kenny, \& Dumont, 1995; Coates, 2006). Student engagement is also defined as the amount of physical and psychological energy that students devote to educationally purposeful activities (Ivala, Gachago, Condy, \& Chigona, 2013). The social features that have attracted millions of people to use Web 2.0 technologies are also capable of getting the students engaged in their learning. In this sense, these online platforms can also be used to encourage students to invest both time and energy in interacting with others in various educational activities (Kuh, 2003; Kuh, Cruce, Shoup, Kinzie, \& Gonyea, 2008; Rutherford, 2012). Consequently, these online tools can give confidence to shy, intimidated, lazy, or bored students and, thus, motivate them to share ideas and to speak their minds. Web 2.0 applications can, therefore, be used to design interactive learning environments where students are engaged in managing their own learning.

A third educational advantage of Web 2.0 applications is that they promote collaborative learning as they provide teachers and students with a single destination where they can remotely, and at various performance levels, work together towards a common goal (Gokhale, 1995). Many education experts have, actually, demonstrated that collaboration is a valuable component of the learning process. They argue that students do not learn well when they are isolated. On the other hand, the frequent recourse to group work enhances students' motivation, self-confidence, self-esteem and success (Hillyard, Gillespie, \& Littig, 2010). Given the collaborative and participatory nature of Web 2.0 applications, students and teachers can, either synchronously or asynchronously, cooperate on different projects and tasks. As such, Web 2.0 supports a constructivist approach to learning in which knowledge is co-produced rather than an approach that lays great emphasis on individual contributions (Stevens, 2009).

The fourth educational benefit of Web 2.0 technologies is that they are a precious repository of teaching and learning resources. In the past, the information concerning any given subject was very scarce, and there were few ways to access it. However, given that Web 2.0 platforms have a large community of users, a great number of learning resources are produced every day. Thus, the huge amount of content that these web-based applications host provides any user with pertinent information on virtually any topic. Thanks to its collaborative nature, Web 2.0 has become one of the valuable resources that many teachers and students have recourse to so as to get authentic learning and teaching materials. These include videos, audio files, text documents, images as well as any piece of information that a teacher or student could wish for.

Given these educational advantages, Web 2.0 technologies can function as an ideal virtual space for language learning and teaching. Thanks to the social features that they integrate, these online platforms can make language learning or teaching more effective, interesting and enjoyable. The online platforms that were initially designed to 
help people interact with each other can also be used to make language learning and teaching faster and more engaging.

In actual fact, by using Web 2.0 technologies, a language enthusiast can be easily put in touch with native speakers, who are 'experts' in the target language. Though the rules governing how a given language is to be written and spoken can be learnt from instructors who are usually non-native speakers, and no matter what exercises or activities are done in class, students often need more opportunities to foster their listening and speaking skills. This is mainly due to the fact that classroom-based tasks are not actual real-life situations. As opposed to formal language learning and teaching settings, Web 2.0 platforms are distinguished by the constant availability of many native 'instructors'. Consequently, these applications provide a live experience in which students or language learners can boost their target language skills in real time. In this way, learning can continue beyond classroom walls and the learner's autonomy and lifelong skills can be enhanced.

Moreover, with or without the teacher's recommendations, passionate language learners can have access to a wide range of online communities where they can get answers to most of their queries, with no need to go through the anxiety of asking questions in class. In addition to the popular and general social networking sites such as Facebook, there are typical online language learning communities that offer lessons, interactive exercises, tests as well as video chat-based conversations with native speakers. Users can, for instance, ask questions for clarification on any points related to the target language, and answers are provided quickly from other native speaking users.

Video sharing websites such as YouTube, Vimeo and Dailymotion are also valuable platforms through which many language skills can be learnt or taught. This collection of online tools, actually, has the potential to create a learning community where every user has a voice (Duffy, 2008). Using these media tools either inside or outside the classroom can foster the students' conversation, listening, and pronunciation skills. The videos that media sharing websites host can also enable students to get exposed to authentic language and to enhance exposure to the world's cultures. And just like other Web 2.0 technologies, media sharing platforms promote learning styles that are more autonomous and student-centred (Watkins \& Wilkins, 2011).

\section{Language learners' and teachers' perceptions towards using Web 2.0}

Having detailed the potential benefits of using Web 2.0 technologies in education and in language learning and teaching in particular, the purpose of the present section is to investigate how both students and language teachers perceive the use of these digital social platforms for language learning and teaching purposes.

\subsection{Research methodology}

To explore the effectiveness of using Web 2.0 technologies in language teaching and learning, a research study was conducted so as to examine how both students and teachers view the potential role that these online tools may play in enhancing the teaching and the learning processes. For this purpose, two web-based anonymous questionnaires were submitted: one to a group of higher education students and another to some university language teachers. Our choice of online rather than paper surveys was dictated by the fact we wanted to reach the majority of students and faculty members, and also to ensure that anonymity of the informants is maintained. Both questionnaires consisted of 
three major parts. The first part was concerned with collecting demographic information about the subjects. The second part focused on the informants' use and usage of Web 2.0 platforms. The third part gathered data about the students' and teachers' perceptions and attitudes towards using these digital tools for language learning and teaching purposes.

The surveys' target population was students from Mohammed V University and language teachers from various Moroccan public and private higher education institutions. The links of both questionnaires were sent by e-mail to 564 students and 137 teachers. The number of students who returned the questionnaire was 382 while that of the teachers was 90.

\subsection{Data processing}

Once the data was collected and processed, it was found out that the great majority of the respondents, be they teachers or students, have a profile in at least one online social network. The most widely used social networking websites amongst the participants are Facebook, LinkedIn, Google+, Viadeo and Twitter. Apart from Facebook, which is the most popular amongst both groups of informants, all other social websites are used on a lesser scale and the position that each of these occupies varies from one population to another. In addition to this range of virtual online communities, the study revealed that respondents use another range of Web 2.0 websites, namely media sharing websites, discussion forums, blogs and wikis.

Concerning the main reasons for using these digital platforms, it was observed that the purpose behind using these social media platforms vary from one subject to another, but all the informants said that they use them for both personal and educational reasons. Students, for instance, use these platforms not only to communicate with others but also to learn. In fact, these social media platforms have become a crucial resource for students in all subjects. Likewise, teachers noted that they make use of Web 2.0 for both private and pedagogical purposes. Indeed, they confirmed that these online platforms provide them with teaching and learning materials and enable them to prepare lessons and assessments.

\subsection{Students' views on using Web 2.0 technologies as language learning tools}

Regarding the use of these digital applications for language learning purposes, the findings revealed that $82 \%$ of the surveyed students noted they use these online tools to improve their language skills and even learn new foreign languages. The most common languages that Moroccan higher education students are interested in learning are given in Fig.1.

As the figure clearly shows, English, which is the dominant language of international communication, is the most popular language that is learnt by Moroccan university students. French and Spanish are also common amongst language learners and are in the second and third positions, respectively. In addition to these languages, students also learn other languages, namely Japanese, German, Italian, Chinese and Turkish. This explicitly justifies that social media platforms are used not only as a means of communication but also as language learning tools.

To get information about the Web 2.0 technologies that students use to practice their language skills, the respondents were asked to select, from a list, the platforms that they resort to. The results are given in Fig. 2. 


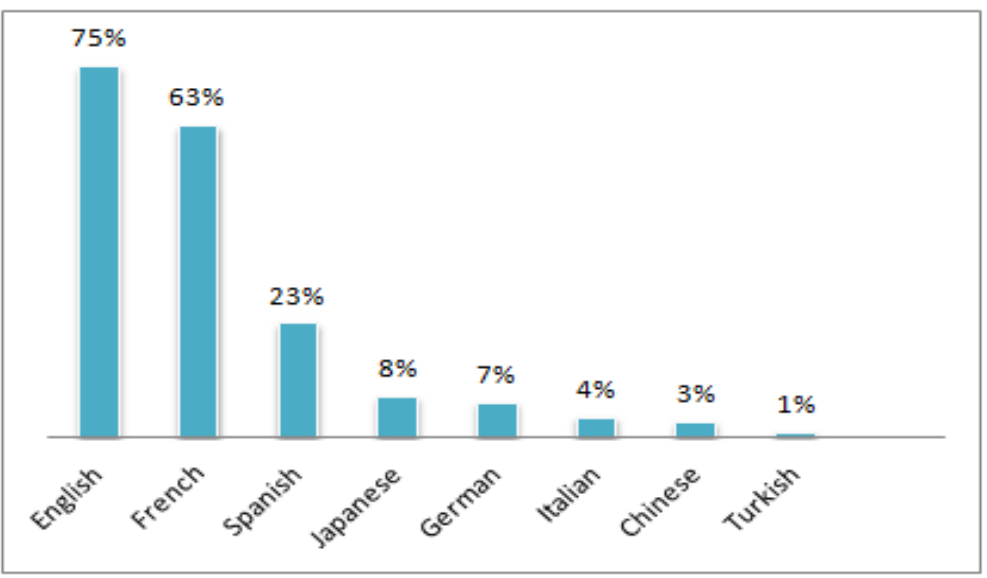

Fig. 1. Languages that students learn via Web 2.0 technologies

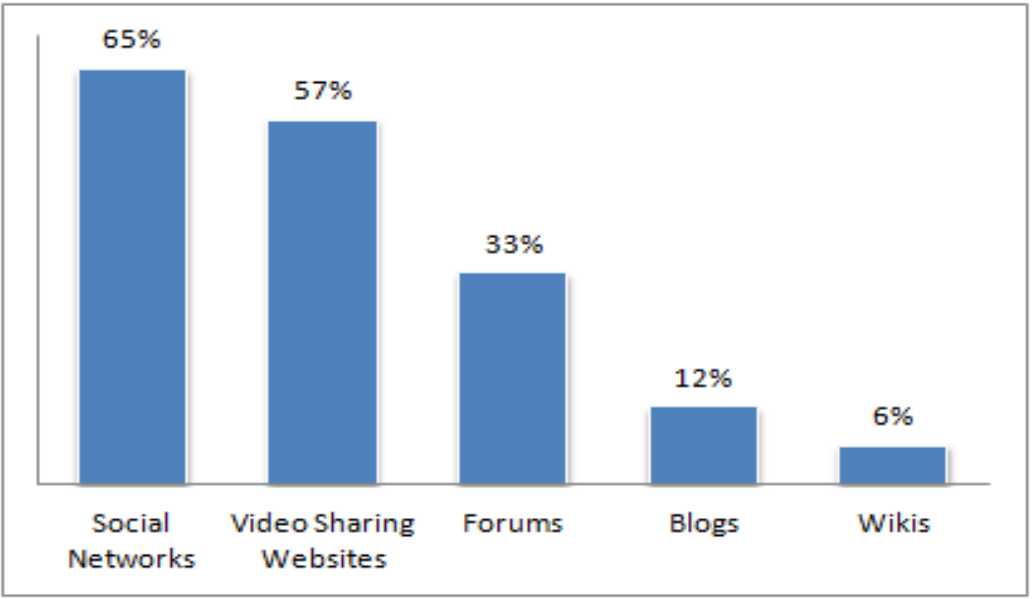

Fig. 2. Web 2.0 technologies that students use

As is clearly seen, students use a variety of applications to enhance their language learning. However, social networks are the most popular tools used for this purpose. This is so because they incorporate features from other social media applications. One good example of these social networks is Facebook. The latter has a huge international community and is, thus, a perfect place to learn languages. On the huge variety of pages that Facebook hosts, users can join conversations without worrying about how they say things. They can add their own comments, ask questions, respond to others and follow topics that might interest them. As such, they can turn a conversation into a deeper discussion and practice language with real world examples through audio and video clips, podcasts and news articles.

In addition to social networks, the respondents mentioned that they opt for other tools to enhance their language learning. These includes media sharing platforms (namely YouTube), which are made use of by $57 \%$ of the subjects, and discussion forums used by $33 \%$ of the informants. Nevertheless, blogs and wikis do not seem to be popular among Moroccan language learners. 
Besides the common social networks such as Facebook and Twitter, there are some Web 2.0 learning platforms that are totally dedicated to language learning. These include structured spaces such as Busuu, Babbel, and Livemocha, which typically provide communities of language learners of various lessons, support and feedback on language learning issues. However, it has been noticed that only few Moroccan higher education students use these platforms.

To have information on Web 2.0 technologies' potential in improving the learners' language proficiency, the students were particularly asked about the usability of Web 2.0 regarding the acquisition process of the four major language skills, namely the two receptive skills (i.e. reading and listening) and the two productive skills (viz. writing and speaking). Specifically, the subjects were asked to rank, on a scale from one to four, the language skills that they improved most. Consider the following Fig. 3.

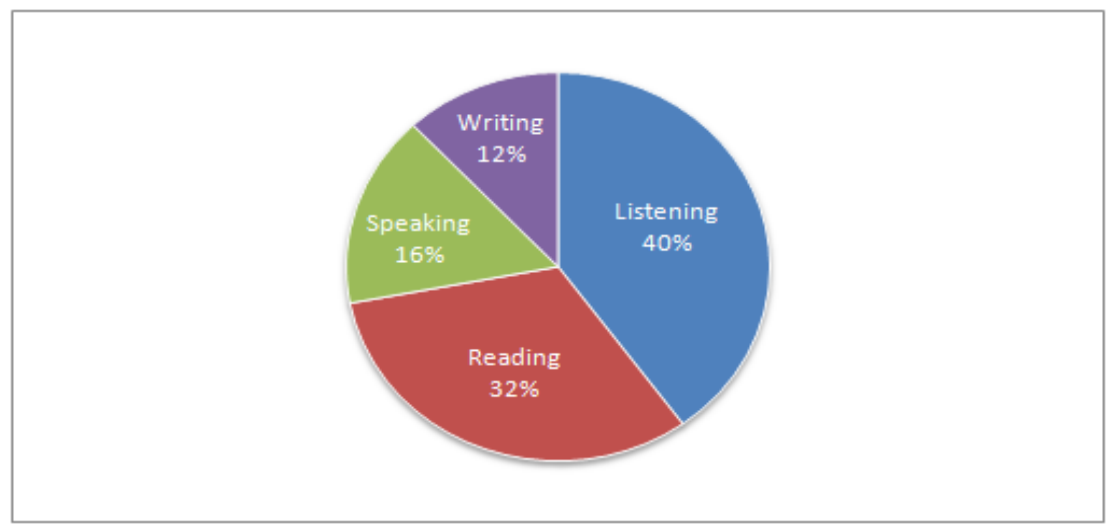

Fig. 3. Students' ratings for each of the four language skills

As the figure shows, the main language skills that the surveyed students reported to improve are the receptive skills: listening (40\%) and reading (32\%). The enhancement of both skills can be justified by the fact media sharing websites, characterized by an overwhelming abundance of materials and resources, enable language learners to listen to different speakers talking about a variety of topics and on various genres (lectures, interviews, stories, songs, etc.). Furthermore, other digital platforms, especially social networks, discussion forums, blogs and wikis provide more opportunities for students to learn and practice their reading skills in authentic curriculum contexts. The third language skill that the respondents claimed to improve via social media is speaking $(16 \%)$. In fact, with the available technology and social media applications (e.g. Skype and WhatsApp, etc.), students have more possibilities to speak with native speakers around the world, a great opportunity to practice their speaking skills in an environment where everybody is there to learn and without being judged. As far as writing is concerned, it was found out that the impact of Web 2.0 technologies on enhancing this skill is less visible.

Now that we have explored the students' views on the use of social media platforms for language learning purposes, our objective in what follows is to explore how faculty members view the potential role that these web-based applications play in improving language and communication skills. 


\subsection{Teachers' attitudes towards using Web 2.0 technologies in language learning and teaching}

To examine the teachers' perceptions on the use of Web 2.0 platforms for language learning and teaching purposes, the surveyed faculty members were firstly asked about the kind of impact that these online platforms could have on students' learning, and on education, in general. The findings indicated that most of the teachers stipulated that these digital applications, actually, have a positive impact as they broaden students' knowledge and understanding in different subject matters. For illustration, see Fig. 4 given below.

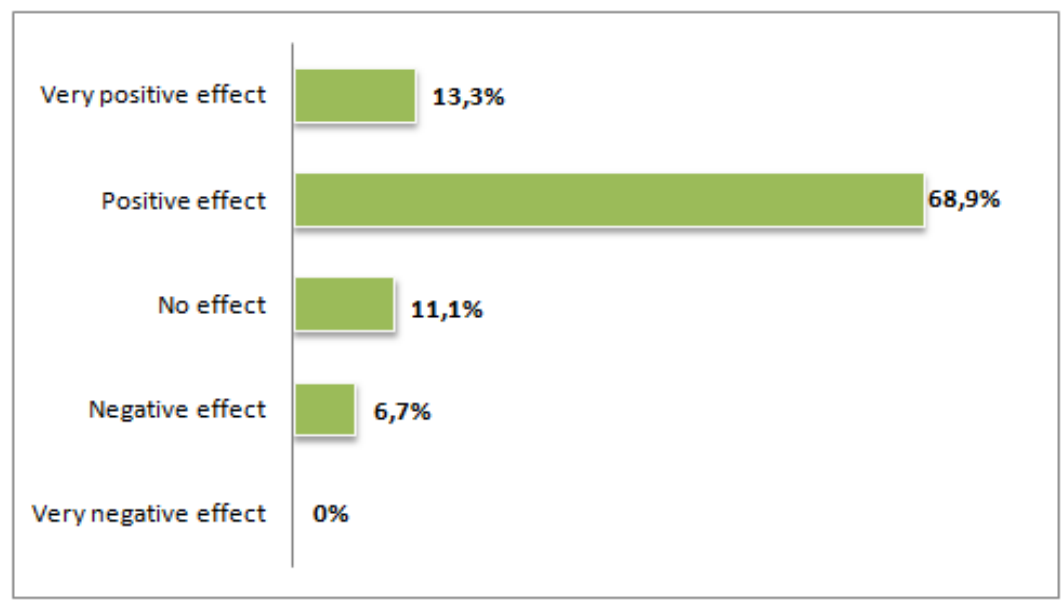

Fig. 4. Faculty views concerning the impact of Web 2.0 on education

As the illustration shows, the majority $(82.2 \%)$ of the surveyed teachers noted that there is a positive impact on using these online tools in education settings. By contrast, $6.7 \%$ of the faculty members stipulated that these platforms negatively influence students' learning. The negative attitude that instructors have towards the use of social media is likely due to the belief that the teacher is the sole provider of information and knowledge, and to the feeling that these technologies distract students from learning (Faizi \& El Fkihi, 2016).

Concerning the potential effect that these Internet-based applications might have on language learning, the teachers were asked to express whether they agree or disagree with the view that Web 2.0 tools help students foster their language and communication skills. The results relating to this issue are summarized in Fig. 5.

As you can clearly see, $82,3 \%$ of the subjects "agree" that these tools do, in fact, enable language learners to enhance their skills. This implies that all the teachers who feel the positive impact of these tools on education in general also converge on the fact that the same tools are capable of enhancing language learning skills. In contrast, the rest of the informants (i.e. 17,7\%) stipulate that these online tools cannot contribute to promoting language learning.

To get more evidence about the impact that Web 2.0 has on language learning, the faculty members who thought that the new digital applications could enhance the students' language and communication skills were also required to rank the four language skills (viz. listening, speaking, reading, and writing), from most to least improving. Fig. 6 exhibits the ratings related to each skill. 


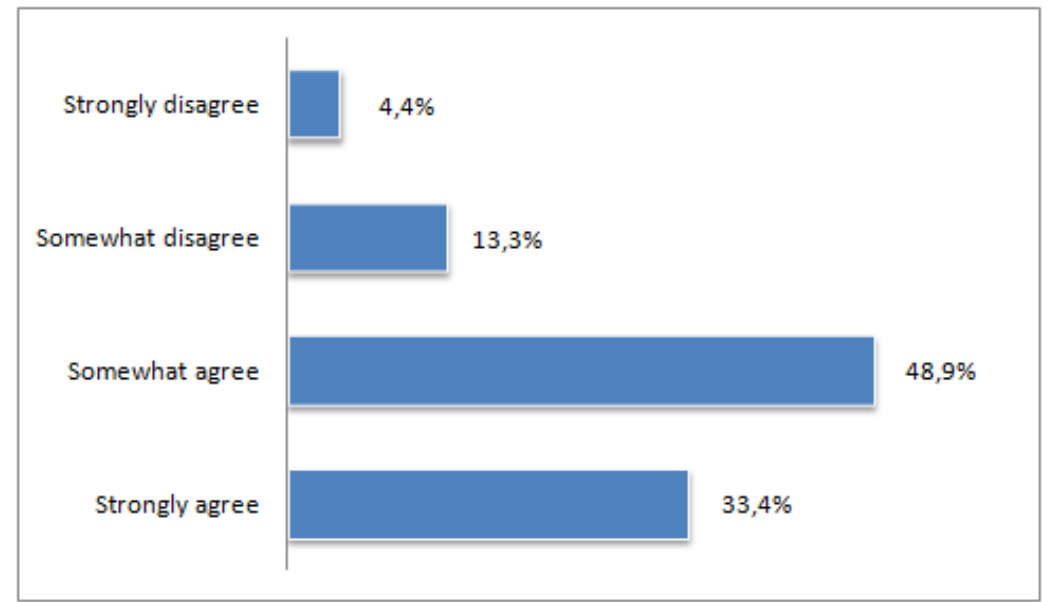

Fig. 5. Faculty views concerning the impact of Web 2.0 on language learning

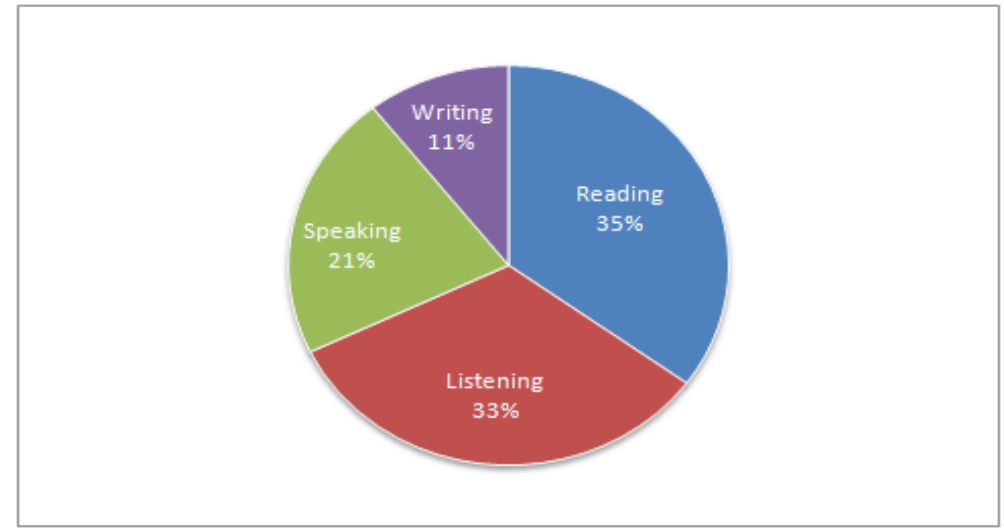

Fig. 6. Teachers' ratings for the four language skills

Apart from a slight difference as to the position that reading and listening occupy in Fig. 3 and Fig. 6, the surveyed language learners and teachers converge on assigning higher ratings to receptive skills and lower ones to productive language skills.

\subsection{Discussion}

The findings above clearly confirm that Web 2.0 technologies have a positive impact on language learning and teaching. However, although all the surveyed students as well as the overwhelming majority of the interviewed teachers are immersed in these social online communities, communication between both parties is very minimal. Only 22,2\% of the interviewed faculty members were found out to interact with students via these online platforms. The rest use these online tools simply to post links to learning resources mainly created by other internet users. In fact, though a lot of instructors agree that using Web 2.0 technologies is beneficial for students' academic performance, many seem to be hesitant in embracing these online applications for fear that the boundary between the teacher and the student can quickly become blurred. According to many teachers, interacting with students via these online communities can just give rise to confrontations. This is why these social websites are mostly used by teachers only as to means to tran sfer 
links and documents to students, and not as teaching platforms. For their parts, students are also interested in preserving privacy and are, thus, concerned with a separation between their online academic lives and their online social lives (Pavelea, 2013). Only a few students were found to like to mix academic and leisure activities. As a consequence, communication between students with instructors on a Web 2.0 platform is a rare occurrence (Faizi, Chiheb, \& El Afia, 2015; Ophus \& Abbitt, 2009).

\section{Conclusion}

This paper aimed at investigating the perceptions of Moroccan higher education students' and teachers' towards using Web 2.0 technologies in language learning and teaching. Results of the study demonstrated that just like students, language faculty members are immersed in these virtual online communities and have recourse to them for private and educational purposes. Nonetheless, despite the fact that the overwhelming majority of the language teachers who took part in the study noted that these Web 2.0 technologies positively influence language learning and teaching, they were still hesitant in effectively integrating these tools into their classrooms. Indeed, while only very few faculty members reported to generate educational content via these platforms, a great number of the interviewed teachers were confined to sharing with their students' resources produced by other Web users. This clearly means that Web 2.0 technologies were used by instructors merely as communication platforms. However, taking into account the positive impact of these digital applications on education and on language learning and teaching in particular, we strongly recommend that language teachers use them whether they are working in fully online, blended, or face-to-face teaching contexts.

\section{References}

Annetta, L. A., Minogue, J., Holmes, S. Y., \& Cheng, M. T. (2009). Investigating the impact of video games on high school students' engagement and learning about genetics. Computers \& Education, 53(1), 74-85.

Chen, P. S. D., Lambert, A. D., \& Guidry, K. R. (2010). Engaging online learners: The impact of web-based technology on college student engagement. Computer \& Education, 54(4), 1222-1232.

Coates, H. (2006). Student engagement in campus-based and online education: University connections. London: Routledge.

Dawson, S. (2006). A study of the relationship between student communication interaction and sense of community. The Internet and Higher Education, 9, 153-162.

Duffy, P. (2008). Engaging the YouTube Google-eyed generation: Strategies for using Web 2.0 in teaching and learning. The Electronic Journal of e-Learning, 6(2), 119130.

Emelyanova, N., \& Voronina, E. (2017). Introducing blended learning in the English language classroom: Students' attitudes and perceptions before and after the course. Knowledge Management \& E-Learning, 9(1), 33-49.

Faizi, R., Chiheb, R., \& El Afia, A. (2015). Students' perceptions towards using Web 2.0 technologies in education. International Journal of Emerging Technologies in Learning (iJET), 10(6), 32-36.

Faizi, R., El Afia, A., \& Chiheb, R. (2013). Exploring the potential benefits of using social media in education. International Journal of Engineering Pedagogy (iJEP), 3(4), 50-53.

Faizi, R., El Afia, A., \& Chiheb, R. (2014). Social media: An optimal virtual environment 
for learning foreign languages. International Journal of Emerging Technologies in Learning (iJET), 9(5), 64-66.

Faizi, R., \& El Fkihi, S. (2016). Incorporating Web 2.0 technologies in education: Opportunities and challenges. In Proceedings of the 28th IBIMA conference on Vision 2020: Innovation Management, Development Sustainability, and Competitive Economic Growth (pp. 3242-3248).

Gokhale, A. A. (1995). Collaborative learning enhances critical thinking. Journal of Technology Education, 7(1): 22-30.

Hao, Q., Barnes, B., Branch, R. M., \& Wright, E. (2017). Predicting computer science students' online help-seeking tendencies. Knowledge Management \& E-Learning, 9(1), 19-32.

Harris, A. L., \& Rea, A. (2009). Web 2.0 and virtual world technologies: A growing impact on IS education. Journal of Information Systems Education, 20(2), 137-144.

Hillyard, C., Gillespie, D., \& Littig, P. (2010). University students' attitudes about learning in small groups after frequent participation. Active Learning in Higher Education, 11(1), 9-20.

Ivala, E., Gachago, D., Condy, J., \& Chigona, A. (2013). Enhancing student engagement with their studies: A digital storytelling approach. Creative Education, 4(10), 82-89.

Junco, R. (2012). The relationship between frequency of Facebook use, participation in Facebook activities, and student engagement. Computers \& Education, 58, 162-171.

Kenny, G., Kenny, D., \& Dumont, R. (1995). Mission and place: Strengthening learning and community through campus design. Westport, CT: Oryx Press.

Kent, M. (2016). Adding to the mix: Students use of Facebook groups and blackboard discussion forums in higher education. Knowledge Management \& E-Learning, 8(3), 444-463.

Kuh, G. D. (2003). What we're learning about student engagement from NSSE: Benchmarks for effective educational practices. Change: The Magazine of Higher Learning, 35(2), 24-32.

Kuh, G. D., Cruce, T. M., Shoup, R., Kinzie, J., \& Gonyea, R. M. (2008). Unmasking the effects of student engagement on first-year college grades and persistence. The Journal of Higher Education, 79(5), 540-563.

Kumar, S., \& Cohn, E. R. (Eds.). (2012). Telerehabilitation. London: Springer-Verlag.

LeNoue, M., Hall, T., \& Eighmy, M. A. (2011). Adult education and the social media Revolution. Adult Learning, 22(2), 4-12.

Ophus, J. D., \& Abbitt, J. T. (2009). Exploring the potential and perceptions of social networking systems in university courses. Journal of Online Learning and Teaching, 5(4), 639-648.

Pavelea, A. (2013). Social media and the new academic environment: Pedagogical challenges. Journal of Media Research, 6(3): 6

Rutherford, C. (2012). Using social media to support student engagement. Retrieved from http://www.drcamillerutherford.com/2012/02/using-social-media-to-supportstudent.html

Stevens, V. (2009). Modeling social media in groups, communities, and networks. TeslEj, 13(3), 1-16.

Watkins, J., \& Wilkins, M. (2011). Using YouTube in the EFL classroom. Language Education in Asia, 2(1), 113-119.

Yu, A. Y., Tian, S. W., Vogel, D., \& Kwok, R. C. W. (2010). Can learning be virtually boosted? An investigation of online social networking impacts. Computers \& Education, 55(4), 1494-1503. 